\title{
Creating space for a critical feminist social work pedagogy
}

\author{
Sarah B. Epstein, Norah Hosken and Sevi Vassos, \\ School of Health and Social Development, Deakin University, Australia.
}

\begin{abstract}
INTRODUCTION: The practice and teaching of western social work is shaped within the institutional context of a predominately managerial higher education sector and neoliberal societal context that valorises the individual. Critical feminist social work educators face constraints and challenges when trying to imagine, co-construct, enact and improve ways to engage in the communal relationality of critical feminist pedagogy.
\end{abstract}

APPROACH: In this article, the authors draw upon the literature and use a reflective, inductive approach to explore and analyse observations made about efforts to engage with a subversive pedagogy whilst surviving in the neoliberal academy.

CONCLUSION: While the article draws on experiences of social work teaching and research in a regional Australian university, the matters explored are likely to have resonance for social work education in other parts of the world. A tentative outline for thinking about the processes involved in co-creating a critical feminist pedagogical practice is offered.

KEYWORDS: critical feminist pedagogy; intersectionality; social work education; critical hope; imagination

AOTEAROA

NEW ZEALAND SOCIAL WORK 30(3), 8-18.

CORRESPONDENCE TO: Sarah B. Epstein sarah.epstein@ deakin.edu.au
Social work is a profession with a stated commitment to the principles and goals of social justice and human rights. Critical social workers take up these principles by casting a lens on the way that power is constructed, used and reproduced. Critical feminist social workers foreground women's diverse experiences of personal, cultural and structural injustice, aiming to make visible women's diverse lived experiences to form the core knowledge base from which to work towards socially just practice. Critical feminist social work pedagogy, shaped by these ideas of what social work is, commits to circulating knowledge about the effects of power. The goal is to enable an ongoing, mutual (re)construction and sharing of the knowledge and skills required to imagine and enact socially just practice. However, the practice and teaching of social work is not context-free, therefore, the profession at large is conditioned by the "social structures, discourses and systems in which it is placed" (Macfarlane, 2016, p. 326). As such, the current and dominant context in which social work education is conditioned are the standardising outcome-based measures of the neoliberal university system. The neoliberal paradigm regulates difference (Burke, 2015), obscures the particular and devalues process. These impacts leave social work education at risk of being complicit in a system that is not capable of accounting for the multiplicity of knowledge and diversity of lived experience, let alone the nuances of the pedagogical process. This article 
represents an attempt at non-compliance with neoliberal hegemony. We (the authors) choose to highlight the particulars of a critical feminist social work pedagogy that aims to make visible the relations of power that condition the lived experiences of educators, students and service users.

Based on an examination of relevant literature and use of a reflective, inductive approach, we explore and analyse observations made about efforts to engage with a subversive pedagogy whilst surviving in the neoliberal academy. The aim is to provide a way of thinking about the processes involved in co-creating a community of learning and practice situated in critical feminist social work pedagogy. The article is structured as follows. First, we introduce and locate ourselves as the collaborative authors of this article. Second, we situate the aims of this article within Australian and international critical feminist social work pedagogy and the ideology and practices of neoliberalism within the higher education context. We draw on anecdotal and structured observations from our learning and practice throughout the article to elucidate understandings of the constraints and challenges we have routinely faced in imagining, co-constructing, enacting and improving ways to engage in the communal relationality of critical feminist pedagogy.

\section{Acknowledging and exploring the benefits of intersectionality}

In positivist, scientific epistemology there is an emphasis on the importance of a neutral, objective stance as a method to eliminate subjective interpretations from the pursuit of knowledge. In contrast, feminist researchers, writers and academics generally contest the assumption that an objectivity free of social context is possible. Further, feminists assert this claim to objectivity often serves to conceal a privileged, dominant, white masculine bias (Smith, 1987). In line with other feminists, rather than striving for objectivity in this article and our work, we commit to practise ongoing critical reflexivity aiming to recognise, examine and understand how our own social locations can influence the construction of knowledge (Hesse-Biber, 2014).

As the three authors of this article, we locate ourselves within our contexts to provide the reader with this information in order to consider its relevance to our discussion and the arguments we make. We share some similarities: being non-Indigenous, Euro settler-background, middle-aged, mothers and social work educators who are living, teaching and learning on the lands of the first nation peoples of Australia, the Aboriginal and Torres Strait Islander peoples.

Following significant periods of direct service work, we each completed PhDs as mature-aged students and became social work educators. An interest in critical social work, feminisms, difference, collaboration, situatedness, relationality, complementarity, and survival in the university system, brought us together. We are curious and constantly seek to learn more about our differences across lived experiences of religion, spirituality, ethnicity, class, sexual orientation, health, socialisation, personality, knowledge and skill sets.

In the next section, we situate the purpose of this article, developing a tentative outline for thinking about the processes involved in co-creating a critical feminist pedagogical practice within an examination of relevant national and international literature. Following Wickramasinghe (2009, p. 112), the engagement with the literature is presented as a "distinctly epistemic project ... a subjective process of knowledge production and meaning-making ... reliant on the [authors'] ...subjectivity and standpoint", rather than an account of all available scholarly research on the topics. Each discussion of a section of the literature is followed by reflective observations explaining how we engage with, and try to enact, the ideas from the literature. 


\section{Social work education within the neoliberal context}

Academic life in the neoliberal university is fast paced and every move the academic makes must be tracked, measured and capable of fitting into standardised data sets and the allocated fields of numerous forms (Clegg \& David, 2006; David, 2015; Hosken, 2017; Kovacs, Hutchison, Collins, \& Linde, 2013; McKusker, 2017; Mountz et al., 2015). The neoliberal paradigm of competencybased outcomes focuses on measuring individual (teacher and student) outputs and standardising teaching outcomes (Clegg \& David, 2006). The pedagogical relationship between teacher and student, as well as the learning relationships between and among class cohorts, are devalued and diminished (McKusker, 2017; Mountz et al., 2015). Within this context, it is increasingly difficult to make visible a pedagogical process grounded in the way that lived experiences (of teacher, student and service user) reflect the multiple systems of oppression and privilege. This is particularly important for the social work pedagogue who tries to embody socially just social work practice.

Feminist social work pedagogues argue that the current neoliberal paradigm represents the antithesis of critical pedagogies, including feminism. Critical pedagogies place priority on recognising the role that social locations and processes play in the ongoing production of knowledge and relations of oppression and privilege (Luke, 1996; Macfarlane, 2016; McKusker, 2017; Mountz et al., 2015). This matters to the teaching of social work practice because the focus of social work, whether it be traditional, radical, progressive, case management focused or grounded in critical theory, is that the client must be considered in light of the social, cultural, political, economic context in which they are positioned (Fook, 2012).

Without the ability or incentive to work with context, the joint social work and feminist goal of transforming society is replaced with the reproduction of "oppressive social arrangements" (Kovacs et al., 2013, p. 234). Feminist pedagogy aims to destabilise the status quo (Crabtree \& Sapp, 2003) in order to work towards social change. This positions both the feminist educator and, potentially, her students in opposition to dominant and powerful structures and practices. Therefore, it is not in the best interests of the neoliberal university to support feminist pedagogical goals (Crabtree \& Sapp, 2003). However, the authors of this article believe it is the responsibility of feminist social work pedagogy to work out ways to do so. Asserting the production of knowledges as the core business of university education, this article reveals the privileging of lived experiences as a core critical feminist social work pedagogy.

Lived experience pays attention to who determines which knowledges shape understanding and response in social work practice, and whose knowledges are reflected in the laws, policies and practices that restrict the lives of non-dominant groups including social work service users. The views from these standpoints of lived experience are not considered as pure windows to truth or reality but rather a place to start investigation (Smith, 1987). Smith's (2005) and Sprague's (2005, p. 52) reading of standpoint theory is adopted in this article as that "which builds strategically on contrasting social locations" to explore the implications of both material realities and fluidities. We aim to take up Collin's (2009, p. xi) challenge to "place the social structural and interpretative/narrative approaches to social reality in dialogue with one another". Feminist and Indigenist perspectives recognise that, by actively including, indeed centring or foregrounding, the experiences and knowledges of those who have been marginalised, we generate fuller accounts of knowledge. The greater the involvement of peoples who have been discriminated against, the higher the possibility that pedagogy and curriculum can include lived experiences, and other forms of knowledge. Pedagogy and curriculum that are inclusive 
of diverse experiences and knowledges improve how social work students engage in critical self-reflection, learn to work with others and contribute to democratising the generation of knowledge (Finn \& Jacobsen, 2003).

\section{Reflection: The need for imagina- tion and community}

Collectively our experience in the university has taught us that the measure of success in the neo-liberal academy is not determined by deeply thought through pedagogical decision making and practices of the academic. Nor is success measured by including diverse and collaborative co-constructions of knowledge. How well a teaching team talks to each other about what it is they do in the classroom and why they have chosen to do it has no subject line in a course review.

Instead, success in the academic system is determined via individual metrics of performance and achievement of standardised and universal outcomes. Attached to this are timelines for handing in cohort statistics and tracking percentages that require us to think about our students and ourselves as measurable units. In the meantime, using a calculator and spreadsheet to account for a whole term of teaching steals time from us.

The entirety of neoliberal policy, procedure and social relations conditions our work selves and our work lives closing down space for discussion and critique of the university (Blackmore, 2007; Hil, 2012; Hosken, 2017). Formal attempts to speak out about the impacts of neoliberalism that preclude the provision of considered, quality teaching have, as elsewhere (Bessant, 2014), been met with disregard, reprimand and ridicule.

We have been working together for over three years now and as the pressure built, we began talking, at first informally, off campus, over food and wine and by the sea. We needed the space to think deeply, to test ideas, to argue about feminism, about social work, about the best ways to reflect socially just social work practice inside the academy. We needed time to identify the social, cultural, political and economic context of the workplace, of the world in which our students lived and where their future clients come from. We met to make visible the particularities of who we felt we were and who we thought we wanted to become. We needed an environment where we could test out our own transformative potential before we could justify making these demands of our students. If we were to teach students to respect the similarities and differences in the lived experiences of clients' lives, we needed to immerse ourselves in a space where we bore witness to, and validated, each other's lives.

These informal meetings solidified the impetus to create a space where we could be immersed in context in order to work out how to change it, to work in ways that foster "critical hope" (Leonard, 1979, cited in Pease, Goldingay, Hosken, \& Nipperess, 2016) and where we could imagine what collaboration looked like. Paying attention to each other's lived experiences of working in the university made us aware of the criticality of working out ways to do this not only with ourselves but also with our students and so we decided to come in from the margins. This mutual, critical sociological imagination (Mills, 1959) is subversive in countering the ideological rhetoric discourse of "there is no other alternative" to the individualism inherent in neoliberalism. Now, formally we meet, discuss, share, and develop teaching and research ideas and we have made ourselves visible as Critical Edge Women (CrEW).

\section{Feminisms}

Understanding what feminist pedagogy means in the higher education teaching 
and learning context starts with identifying what feminism means in the $21^{\text {st }}$ century. Contemporary feminist analysis recognises that gender cannot be the sole analytical category if we are to truly recognise and understand the multiple social locations in which women are positioned (Gray \& Boddy, 2010). However, the personal is political feminist statement remains as salient and useful as ever. This is because feminist analysis seeks to understand the complex cultural discourses and multiple structural systems that women interact with and through which women's lived experiences are shaped (Clegg \& David, 2006).

The feminist cause is also about identifying opportunities for agency and equality at both the individual but also the social and collective levels (Dore, 1994; Clegg \& David, 2006; Gray \& Boddy, 2010). This is a key reason why feminist academics consider the learning and teaching context as a viable, legitimate and important location for activism. The integration of activism in pedagogical activity affords students opportunities to engage experientially with the practice of socially just social work with service users.

\section{Reflection: CrEW as a space for feminist activism}

As Critical Edge Women (CrEW) we meet formally on a regular basis in the university workplace. While gender is not the sole analytic category we employ to make sense of our lived experiences in the teaching and learning space, the personal as political is the starting point for identifying the complex discourses and structural systems that condition our academic selves. Ensuring that there are regular and substantial amounts of time allocated for critical collective discussion provides reprieve from the isolated siloing that is a function of the neoliberal paradigm. In this space, we are not sole practitioners making teaching and learning choices. Instead, we assume relational positions as critical friends in discussion with a view to supporting each other to sharpen our thinking and improve the depth and quality of our work.

Collectively we occupy different cultural, class and religious social locations. We have arrived at academia via different theoretical and feminist avenues. Our social work practice experiences come from health systems, community organisations, feminist collectives and the violence against women sector. Some of us work full time and one works part time. We live regionally and in urban environments. We are all carers with differently aged children in fluid stages of love, resentment and hope for the world, our partners, our children and our lives. We argue, and we rage, and we rely on our differences to hold each other accountable to our assumptions, partial understandings and biases. These discussions carry through into our wider interactions, the questions we ask, the curriculum choices we make and the shape of our interactions with students.

As a social and collective space, $\mathrm{CrEW}$ creates opportunities for us to identify potential for agentic activity; that is, what do we want to change, how are we positioned in ways to be able to enact change and what would this activity look like? The first step was to legitimate collective, formal space to take time back and create opportunity for understanding and co-construction of knowledge. Primarily, CrEW is an attempt to work out all of the ways the university as a teaching and learning space can be a location for our feminist activism.

\section{Feminisms and social work}

There is a strong argument for the place of feminism in social work education that is about more than the disproportionate overrepresentation of women in the profession and the service user populations (Morley, 
2009; Payne, 2014). Feminist practice in Australian social work was first articulated in the 1970s and was an attempt to address the gender blindness of social work (Morley, 2009). Feminism and social work share fundamental principles and indeed reflect shared philosophies and goals (Dore, 1994). Both the Australian Association of Social Workers and the International Federation of Social Workers identify human rights and social justice as core values and objectives. Violence against women and girls, economic disadvantage and patriarchal culture and politics all pose a significant threat to women's human rights and obstruct social justice. Gender equity issues that impact on the lives of service users who identify as female is consequently core business for social work. Further, in the recent compilation of Contemporary Feminism in Social Work Practice, the editors assert that feminism is indeed fundamental to both social work ethics and values but also professional identity and practice (Wendt \& Moulding, 2016).

\section{Reflection: Collective nourishment to imagine, hope and be imperfect}

In the CrEW discussions and space, we provided and felt the healing protection of loyalty and care in a community. This provided safety, nourishment and the "capacity to imagine something rooted in the challenges of the real world yet capable of giving birth to that which does not yet exist" (Lederach, 2005, p. ix). Inspired by Audre Lorde (2007), we longed for something different:

The possible shapes of what has not been before exist only in that back place where we keep those unnamed, untamed longings for something different and beyond what is now called possible, and to which our understanding can only build roads. (Lorde, 2007, p. 121)

As we learned and explored more about each other's social locations we felt more knowledgeable. Ideas were shared for creating relational spaces with students where their lived experiences and diverse social locations become part of creating the pedagogy and content of the subjects we taught. Often, straight after the excitement of sharing ideas, we came up against the realisation that enacting this relational space with students would be invisible, unvalued and unpaid work in the academy; work that often stole time away from us and our families. We would oscillate between feeling hopeless and feeling critical hope (Leonard, 1979, cited in Pease et al., 2016). Encouragement and strength was gained from reading and sharing the works of other feminist academics about their efforts to resist neoliberalism, particularly by the calls for "collectivity" and "slow scholarship" (Mountz et al., 2015). Discussions about the inevitable imperfection of trying to embody the values and beliefs of feminist social work within the worst of neoliberal times made us sad, but also enabled us to be less judgemental about others and ourselves. Openness about our strategic, or just exhausted, complicity in neoliberal organisational values and practices allowed us to consider the material reality of the dominance of neoliberalism. Rather than setting ourselves up as heroic feminist social work activists, we allowed ourselves to imagine and imperfectly try to resist or transform, often in small ways. Humility came from awareness of the privilege of aspects of our own situations. This privilege included having a relatively high wage generating disposable income and good housing as compared to the lives of many of our female identifying students, and the service users they worked with on placement, as they lived in poverty, juggled demands of caring, and faced discrimination and micro-aggressions without the protections afforded by a secure income. These disadvantages we framed as human rights concerns and in the CrEW space we began to map out 
the gender equity issues and intersecting systems of oppression that faced both our students and their social work clients.

\section{Critical feminist social work}

Critical social work sits within the tradition of progressive social work and is informed by critical theory. Macfarlane (2016, p. 327) defines critical social work as:

...A social work lens that acknowledges and addresses: structural inequalities and inequitable power dynamics; the impact of discourse on lived experience; the importance of diverse knowledge systems, social work values and ethics; and critical reflection for progressive practice.

In essence, this means that critical social work seeks to understand the way that power is constructed, used and reproduced. Some of the ways that critical social workers do this include: questioning assumptions about truth and knowledge that are taken for granted; seeking information from multiple sources to deepen understandings of lived experiences; recognising that the personal is political and our everyday actions are political in nature; and acknowledging that language is powerful in both reflecting and reproducing discourse as well as capable of introducing alternative discourses.

Critical social workers have a longstanding interest in the emancipation of the oppressed as well as an interest in the ways in which oppressed groups exercise agency and personal power. More recently, critical social work has turned the focus on relations of power towards the machinations of privilege in order to redress and understand the marginalising and othering effects of objectifying oppressed groups, communities, cultures and people (Pease et al., 2016). This attention to the behaviours of those who benefit from discrimination aims to re-distribute responsibility for change.
Critical social work has been influenced by feminist principles and goals (Allan et al., 2009). Many critical social workers argue that enacting critical social work practice demands consideration of gender inequality and the intersections at which clients who identify as women are positioned in ongoing ways (Allan, Briskman, \& Pease, 2009; Fook, 2012; Pease et al., 2016). Critical feminist social work seeks to understand how women's experiences engage with other systems of oppression in order to understand discrimination and disadvantage at the intersections of race, class, culture, age, ability and sexuality (Briskin \& Coulter, 1992; Shrewsbury, 1998; Webber, 2006). Critical feminist social work takes stock of what gender equality and social justice look like and considers the role that social work can play in achieving them.

A critical feminist social work approach suggests there are some unifying principles that are used to co-create a critical feminist pedagogy and practice which is informed by, and suited to, the local context. In Australia, critical feminist pedagogy has to be informed by the history and ongoing realities of colonisation, invasion and whiteness, and the need to foreground the works of Aboriginal social work academics.

\section{Reflection: Interrogating the white- ness of Australian social work and foregrounding the works of Abo- riginal social work academics.}

Drawing on the work of Aboriginal and Torres Strait Islander scholars and their allies (Bennett, 2013, 2015; Bennett, Green, Gilbert, \& Bessarab, 2013; Bennett, Redfern, \& Zubrzycki, 2017; Green \& Baldry, 2008, 2013; Land, 2012, 2015; Zubrzycki et al., 2014), we aimed to learn and prioritise the processes of problematising and decolonising ourselves and our teaching. Examples of this included contributing to efforts to increase the diversity of the social work teaching team to better reflect the 
demographic of social work students and service users. Another example is situating the works of Aboriginal and Torres Strait Islander scholars in positions of prominence in curriculum alerting students to the cutting-edge nature of this knowledge for social work, rather than Indigenous content being a discrete add-on topic at the end of units of study. We have built on the work of others to adapt and develop ways to engage with students in a process of exploring the intersectionality of oppression and privilege in our lives and social work practice.

\section{Critical feminist social work pedagogy}

The teaching of women's studies, the advent of self-identified feminist academics and the articulation of feminist pedagogy is approximately 50 years young (David, 2015). Despite this, feminist academics have been prolific contributors to both research and the scholarship of teaching and learning. Feminist pedagogy has come to be a priority for feminists in the academy (Baiada \& Jensen-Moulton, 2006). However, there is not one singular approach as feminist pedagogy also reflects the diversity of the feminist academic cohort (Webber, 2006).

The feminist scholarship of teaching and learning offers a critique of traditional pedagogy (Cuesta \& Witt, 2014). Overall, the feminist pedagogical project focuses on resistance to phallocentric knowledges (Luke, 1996; Ylostalo \& Brunila, 2017) understanding gendered relations of power and making these power arrangements visible (Briskin \& Coulter, 1992; Webber, 2006). Feminist pedagogues argue that traditional pedagogy and phallocentric knowledges obscure women's lived experiences, histories, achievements, concerns and entitlements. Feminist pedagogy is a driving force that shifts the focus of study towards understanding the lived experiences of women (Borshuk, 2017; Cuesta \& Witt, 2014; David, 2015; Dore, 1994;
Forrest \& Rosenberg, 1997; Kovacs et al., 2013; McCusker, 2017; Shrewsbury, 1993; Chung, 2016). Gender and its intersections with race, class, culture, age, ability and sexuality, is the core analytic category that distinguishes feminist pedagogy from other forms of critical pedagogical theories (Briskin \& Coulter, 1992).

Feminist pedagogy is complex because it is informed by, and interacts with, theory and practice connected to broader feminist struggle, therefore the pedagogical goal is concerned with contributing to change in gender relations on a societal level. Critical feminist social work pedagogy also bears in mind the service users' own gendered positioning. Further, it looks at pedagogical strategies for ensuring accountability to the client for the production of knowledge and descriptions of her experience that reproduce problematic categories of identity. In so doing, feminist critical social work pedagogy works with knowledges that reveal the personal, cultural and structural contexts within which the service user is positioned. It also privileges lived experience in efforts to bring her in from the margins and promote social work practice that does not other her. Critical feminist social work pedagogy aligns with the centrality of women's lived experiences in "understanding and the development of knowledge" (David, 2004, p. 103). This is the hallmark of feminist pedagogy.

\section{Reflection: Bridging the gap through collective action}

As early career academics, we have often felt overwhelmed by the publish-or-perish culture that permeates the neoliberal academy. Our ideal is to contribute well to social work scholarship in ways that align coherently with our critical feminist social work ethos. Our practical reality is the institutional push to continually demonstrate our value in terms of the number and impact of our research publications. The credibility gap between our ideal and our reality was often the main theme in our early discussions as 
the CrEW. Through these discussions, we started to become aware of how we had actively committed to a process of mutual engagement, at a level that was deeper than the professional relationships we had established in our work in other groups within the neoliberal academy. Most importantly, in line with our critical feminist values, we were continually negotiating issues of power, collegiality, competition and trust as part of our mutual engagement. We were starting to build a shared repertoire of practices, language and history that enabled a collective approach to meaning making. Ultimately, we were carving out a space within which we could start visualising different ways to respond to the neoliberal metrics defining our expected work outputs, whilst simultaneously resisting neoliberal ways of working.

The next step was to join up our individual work goals and position ourselves to capitalise on the power of collectivity. More specifically, we committed to joining as the CrEW in our research and advocacy work around women and social work pedagogy. At the time of making this commitment, we were all working on different research and writing projects individually. Although we each had a basic understanding of each other's work, it was not until the decision to join up around some of this work that we started to more fully appreciate the differences in our thinking models and approaches to the work in this space. We discovered that homogeneity of individual work goals is not a precondition for achieving a joined up approach to our work. Rather, we experience our differences as a productive force. It is the ongoing process of collective negotiation around these differences that propels our shared accountability and coherence as a community of learning.

We currently have three projects that we are working on. The first project is our reflection on the development of $\mathrm{CrEW}$ as a community of learning situated within a critical feminist social work pedagogy. The second draws together reflections on how we use critical hope and knowledge co-creation as pedagogical strategies to resist and disrupt the neoliberal discourses and regimes of the higher education system. The third is a mixed methods study that seeks to deepen understandings of the lived experience of social work students with caring responsibilities on placement. Our aim is to co-author all articles and co-lead the advocacy activities emerging from this joint work.

\section{Conclusion}

Social workers are in a privileged and unique position to bear witness to women's storied lives. Feminist social work pedagogues therefore have the opportunity to learn with and teach each other, and students, about the importance of these stories in order to understand the conditions in which women live. In this article, we have engaged with the literature and our own observations to sketch out some of the principles and process we are using to co-create practices situated in critical feminist social work pedagogy, from our social locations in the Australian context. Our work started with conversations that sought to place social structural and interpretative/narrative approaches to social reality whilst also acknowledging and exploring the benefits of intersectionality. These conversations fuelled the desire to create a space for community and collective nourishment to imagine, hope and be imperfect. During our conversations we continually acknowledged the normality of oscillation between feeling hopeless and feeling critical hope in the imperfect process of trying to resist the metrics of individualism within neoliberalism. We also interrogated the whiteness of Australian social work and foregrounded the works of Aboriginal social work academics. The work continued by joining up our work goals, collaborating and sharing our work efforts 
ultimately for the benefit of the students and service users we work with. The next step for us will be explicitly exploring with students how to improve our attempts at feminist pedagogical practice. We share these experiences, processes and principles as part of contribution to a conversation and, in the hope they may have relevance for others to adapt for other social locations and contexts.

\section{References}

Allan, J., Briskman, L., \& Pease, B. (Eds). (2009). Critical social work: Theories for a socially just world (2nd ed.). Crows Nest, NSW: Allen \& Unwin.

Baiada, C., \& Jensen-Moulton, S. (2006). Building a home for feminist pedagogy. Women's Studies Quarterly, 34(3/4), 287-290.

Bennett, B. (2013). The importance of Aborginal and Torres Strait Islander history for social work students and graduates. In B. Bennett, S. Green, S. Gilbert, \& D. Bessarab (Eds.), Our voices: Aboriginal and Torres Strait Islander social work (pp. 1-22). South Yarra, Australia: Palgrave Macmillan.

Bennett, B. (2015). "Stop deploying your white privilege on me!"Aboriginal and Torres Strait Islander engagement with the Australian Association of Social Workers. Australian Social Work, 68(1), 19-31.

Bennett, B., Green, S., Gilbert, S., \& Bessarab, D. (2013). Our voices: Aboriginal and Torres Strait Islander social work. South Yarra, VIC: Palgrave Macmillan.

Bennett, B., Redfern, H., \& Zubrzycki, J. (2017). Cultural responsiveness in action: Co-constructing social work curriculum resources with Aboriginal Communities. The British Journal of Social Work, 48(3), 808-825.

Bessant, J. (2014). "Smoking guns": Reflections on truth and politics in the university. In M. Thornton (Ed.), Through a glass darkly: The social sciences look at the neoliberal university (pp. 463-516). Canberra, ACT: Australian National University Press.

Blackmore, J. (2007). Equity and social justice in Australian education systems: Retrospect and prospect. In W. Pink \& G. Noblit (Eds.), International handbook of urban education (pp. 249-264). Dordrecht, Netherlands: Springer.

Borshuk, C. (2017). Managing student disclosure in class settings: Lessons from feminist pedagogy. Journal of the Scholarship of Teaching and Learning, 17(1), 78-86.

Briskin, L., \& Coulter, R. (1992). Feminist pedagogy: Challenging the normative. Canadian Journal of Education, 17(3), 247-263.

Burke, P. (2015). Re/imagining higher education pedagogies: Gender, emotion and difference. Teaching in Higher Education, 20(4), 388-401. doi:10.1080/13562517.201 5.1020782

Chung, Y. (2016). A feminist pedagogy through online education. Asian Journal of Women's Studies, 22(4), 372-391.

Clegg, S., \& David, M. (2006). Passion, pedagogies and the project of the personal in higher education. Twenty-First Century Society, 1(2), 149-165. doi:10.1080/17450140600906989

Collins, P. H. (2009). Foreword: Emerging intersections, building knowledge and transforming institutions. In B. Dill \& R. Zambana (Eds.), Emerging intersections: Race, class and Gender in theory, policy and practice (pp. VII-XIII). New Brunswick, NJ: Rutgers UP.

Crabtree, R., \& Sapp, D. (2003). Theoretical, political, and pedagogical challenges in the feminist classroom: Our struggles to walk the walk. College Teaching, 51(4), 131-140.

Cuesta, M., \& Witt, K. (2014). How gender conscious pedagogy in higher education can stimulate actions for social justice in society, Social Inclusion, 2(1), 12-23.

David, M. (2004). Feminist sociology and feminist knowledges: Contribution to higher education pedagogies and processional practices in the knowledge economy, International Studies in Sociology of Education, 14(2), 99-124. doi:10.1080/0962021040020121

David, M. (2015). Gender \& education association: A case study in feminist education? Gender and Education, 27(7), 928-946. doi:10.1080/09540253.2015.1096923.

Dore, M. (1994). Feminist pedagogy and the teaching of social work practice. Journal of Social Work Education, 30(1), 97-106.

Finn, J. L., \& Jacobson, M. (2003). Just practice: Steps toward a new social work paradigm. Journal of Social Work Education, 39(1), 57-78.

Fook, J. (2012). Social work: A critical approach to practice (2nd ed.). London, UK: SAGE Publications.

Forrest, L., \& Rosenberg, F. (1997). A review of the feminist pedagogy literature: The neglected child of feminist psychology. Applied \& Preventive Psychology, 6(1), 179-192.

Gray, M., \& Boddy, J. (2010). Making sense of the waves: Wipeout or still riding high? Affilia, 25(4), 368-189.

Green, S., \& Baldry, E. (2008). Building indigenous Australian social work. Australian Social Work, 61(4), 389-402.

Green, S., \& Baldry, E. (2013). Indigenous social work education in Australia. In B. Bennett, S. Green, S. Gilbert, \& D. Bessarab (Eds.), Our voices: Aboriginal and Torres Strait Islander social work (pp. 166-177). South Yarra, VIC: Palgrave Macmillan.

Hesse-Biber, S. (2014). Feminist research practice: A primer (2nd ed.). Los Angeles, CA: Sage Publications.

Hil, R. (2012). Whackademia: An insider's account of the troubled university. Sydney, NSW: NewSouth Publishing.

Hosken, N. (2017). Exploring the organisation of social injustice in Australian social work education (Unpublished doctoral thesis). University of Tasmania, Tasmania.

Kovacs, P., Hutchison, E., Collins, K., \& Linde, L. B. (2013). Norming or transforming: Feminist pedagogy and social work competencies. Affilia: Journal of Women and Social Work, 28(3), 229-239.

Land, C. (2012). The politics of solidarity with indigenous struggles in Southeast Australia (Unpublished doctoral thesis). Deakin University, VIC, Australia.

Land, C. (2015). Decolonizing solidarity: Dilemmas and directions for supporters of indigenous struggles. London, UK: Zed Books. 
Lederach, J. (2005). The moral imagination: The art and soul of building peace, Vol. 3. New York, NY: Oxford University Press.

Lorde, A. (2007). Sister outsider. New York, NY: Crown Publishing Group.

Luke, C. (1996). Feminist pedagogy theory: Reflections on power and authority. Educational Theory, 46(3), 283-302.

Macfarlane, S. (2016). Education for critical social work: Being true to a worthy project. In B. Pease, S. Goldingay, N. Hosken, \& S. Nipress (Eds.), Doing critical social work: Transformative practices for social justice. Crows Nest, NSW: Allen \& Unwin.

McCusker, G. (2017). A feminist teacher's account of her attempts to achieve the goals of feminist pedagogy, Gender and Education, 29(4), 445-460. doi:10.1080/09540253.2017.1290220

Mills, C. (1959). The sociological imagination. New York, NY: Oxford University Press.

Morley, C. (2009). Using critical reflection to improve feminist practice. In J. Allan, L. Briskman, \& B. Pease (Eds.) Critical social work: Theories and practices for a socially just world (2nd ed., pp. 149-159). Crows Nest, NSW: Allen \& Unwin.

Mountz, A., Bonds, A., Mansfield, B., Loyd, J., Hyndman, J., Walton-Roberts, M., ... Hamilton, T. (2015). For slow scholarship: A feminist politics of resistance through collective action in the neoliberal university. ACME: An International Journal for Critical Geographies, 14(4), 1235-1259.

Payne, M. (2014). Modern social work theory (4th ed.). Basingstoke, UK: Palgrave Macmillan.

Pease, B., Goldingay, S., Hosken, N., \& Nipperess, S. (2016). Doing critical social work: Transformative practices for social justice. Crows Nest, NSW: Allen \& Unwin.

Shrewsbury, C. (1998). What is feminist pedagogy? In M. Rogers (Ed.), Contemporary feminist theory (pp. 167-171). Boston, MA: McGraw-Hill.

Smith, D. E. (1987). The everyday world as problematic: A feminist sociology. Toronto, ONT: University of Toronto Press.

Smith. D. (2005). Institutional ethnography: A sociology for people. Lanham, MD: AltaMira Press.

Sprague, J. (2005). Feminist methodologies for critical researchers: Bridging differences. Lanham, MD: AltaMira.

Webber, M. (2006). Transgressive pedagogies? Exploring the difficult realities of enacting feminist pedagogies in undergraduate classrooms in a Canadian university. Studies in Higher Education, 31(4), 453-467. doi:10.1080/03075070600800582

Wendt, S., \& Moulding, N. (2006). Contemporary feminisms in social work practice. New York, NY: Routledge.

Wickramasinghe, M. (2009). Feminist research methodology: Making meanings of meaning-making. London, UK: Routledge.

Ylöstalo, H., \& Brunila, K. (2017). Exploring the possibilities of gender equality pedagogy in an era of marketization. Gender and Education, 30(7), 917-933. doi:10.1080/09540253.2017.1376042
Zubrzycki, J., Green, S., Jones, V., Stratton, K., Young, S., \& Bessarab, D. (2014). Getting it right: Creating partnerships for change: Integrating Aboriginal and Torres Strait Islander knowledges in social work education and practice: Teaching and Learning Framework. Sydney, NSW: Australian Government Office for Learning and Teaching. 